\title{
Biomass yield development of early, medium and late Maize varieties under a future climate in Lower Saxony, Germany
}

J. F. Degener and M. Kappas

University of Göttingen, Institute of Geography, Göttingen, Germany

Received: 30 April 2014 - Accepted: 2 June 2014 - Published: 16 June 2014

Correspondence to: J. F. Degener (jdegene@gwdg.de)

Published by Copernicus Publications on behalf of the European Geosciences Union.

Maize yield

development in

Lower Saxony

J. F. Degener and

M. Kappas

Title Page

Abstract

Introduction

Conclusions

References

Tables

Figures

14

$\rightarrow 1$

4

Back

Close

Full Screen / Esc

Printer-friendly Version

Interactive Discussion 


\section{Abstract}

Lower Saxony, with a total land area of about $46500 \mathrm{~km}^{2}$, constitutes one of the most important agricultural areas in Germany and thus within Europe. Roughly one third of its agricultural area is used for maize cultivation and as of today only few information

5 exist on how a future changing climate will affect its local growing conditions. Thus the newly developed carbon-based crop model BioSTAR and a high-resolution regional climate data-set (WETTREG) were used to evaluate the change in biomass yields of an early, medium and late maize variety. The climate input data is based on the SRES A1B scenario, with a potential fertilization effect or better still, an increased water use efficiency due to rising $\mathrm{CO}_{2}$ levels, taken into account. The biomass yield for all varieties was calculated for each year from 2001 until 2099 on a total of 91014 sites. The results suggest clearly differentiated development paths of all varieties. All three show a significant positive trend until the end of the century. However the medium variety shows a statistical significant decline of $5 \%$ during the first 30 years and only a slight recovery towards $+5 \%$ around the century's end. The late variety has the clearest and strongest positive trend, with partially more than $30 \%$ increase of biomass yields around the end of the century or $+25 \%$ mean increase in the last three decades. The early variety can be seen as in-between, with no negative but also not an as strong positive development path. All varieties have their strongest increase in yields after the mid of the 21st century. Statistical evaluation of these results suggests that the shift from a summer rain to a winter rain climate in Germany will be the main limiting factor for all varieties. In addition summer temperatures will become less optimal for all maize crops. Only if the plants can supply themselves sufficiently with water outside of the increasingly dry summer months, when also temperatures are much more favorable, an increase in biomass yields is feasible. As the data suggests the increasing atmospheric $\mathrm{CO}_{2}$ concentrations will play a critical role in reducing the crops water uptake, thus enabling yield increases in the first place.
BGD

11, 9103-9134, 2014

Maize yield

development in

Lower Saxony

J. F. Degener and

M. Kappas

Title Page

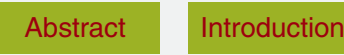

Conclusions References

Tables

Figures

14

$\rightarrow 1$

$\triangleleft$

Back

Close

Printer-friendly Version

Interactive Discussion 


\section{Introduction}

With a production of around $875 \mathrm{Mt}$, maize was the second most grown crop on earth in 2012 , only surpassed by sugarcane and surpassing rice (3rd $718 \mathrm{Mt}$ ) and wheat (4th $675 \mathrm{Mt}$ ). However in terms of nutrition, rice and wheat provided around 3.8 times more 5 calories to the world's average human (FAO, 2014). This spread in the data is a clear indicator for the variety of usage that maize allows for, from its first and foremost use as feed for livestock to a raw material for energy purposes.

As of 2012, like most years before, Lower Saxony (LS) constituted Germany's largest maize producer, accounting for more than a quarter of the $94.56 \mathrm{Mt}$ total German production, while extending over merely $13 \%$ of Germany's overall territory. This is due to an over-average yield of $50.6 \mathrm{tha}^{-1}$ (avg. Germany $46.4 \mathrm{tha}^{-1}$ ) combined with a relative large cropping area of $27 \%$ (avg. Germany $17 \%$ ) of the total utilized agricultural area (DeStatis, 2013).

Around the early 1980's the cropping area of LS for silage Maize leveled out at 15 around 220000 ha for several years. Around 2004 this began to change rapidly. Within five years the area nearly doubled, after less than than a decade the area already amounted to 514000 ha in 2012 (LWK, 2014a). An early look into the matter (Hoeher, 2007) did not show any increase in the local livestock nor a dramatic change in livestock diet or related im- or exports. Even more, the maize cropping area for feed receded by 30000 ha between 2004 and 2007. Energy Maize however, in LS used predominantly as a regenerative power source, showed an increase in cropping area by 38000 ha in only one year. Therefore it can be safely assumed that this increase in cropping area was due to reasons other than livestock farming. While there are some propositions for alternatives to this extensive maize cultivation (NMELVL, 2012; LWK, 2014b) its known production strategies and biomass yields will make it hard for any competing crop to replace maize. Thus it can be assumed that maize will be around for some time, raising the question how changing regional or local conditions will affect its yield potential.
BGD

11, 9103-9134, 2014

Maize yield

development in

Lower Saxony

J. F. Degener and

M. Kappas

Title Page

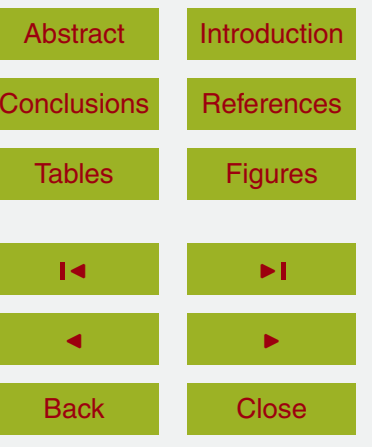

Full Screen / Esc

Printer-friendly Version

Interactive Discussion 
Wolf and van Diepen (1995) did an early estimation of the European grain maize yield potential, basically coming to the conclusion that no large changes are to be expected for the central part of the European Community and thus for LS. This outlook has not changed dramatically in present day studies (Supit et al., 2012), generally suggesting 5 no trend or seldom a positive trend in rainfed maize yields for most parts of Germany. Spatial surveys covering only Germany in its entirety are relatively rare. However, it is often pointed out that maize already grows near optimal conditions in Germany and is as of today already limited through drought stress in its main growing period of July and August (Meyer et al., 2009; Taube and Herrmann, 2009). The expected further - decline in summer precipitation of around $30 \%$ for some areas in Germany (Jacob et al., 2008), however uncertain this change might be, would thus strongly limit the growing conditions of maize in these regions.

In part probably owed to the administrative structure in Germany, the assessment of climate change impacts on crops yields was mostly done on a federal state level. 15 A wide variety of approaches (differences in climate model and dataset, crop model, reference period etc.) make a direct comparison often difficult at least. However, results from regions close to LS are still of special interest for comparison.

The federal state of Hesse, directly to the south of LS, shows a regional differentiated pattern with a positive maize yield trend (up to $+15 \%$ ) in the southern part and a neutral to negative (mostly around $-10 \%$ ) northern part in middle of the 21st century under the SRES B2 scenario (USF, 2005). To the south-west of LS lies North Rhine-Westphalia. Fröhlich (2010) did show that most of the state will profit from a changing climate from an silage maize yield increase of around 2-4\% (B1 scenario) or 3-7\% (A1B scenario) until 2050. Saxony and Thuringia, both to the south-east of LS, have a generally negative development until 2050 (A1B) with a decline in maize yields of roughly $-10 \%$ (Mirschel et al., 2008, 2012). Especially the study for Thuringia does show how wide these results may spread, even if climate model, scenario and crop model are kept the same. Four alternative approaches, including more or less progress in cultivation and
BGD

$11,9103-9134,2014$

Maize yield development in

Lower Saxony

J. F. Degener and

M. Kappas

Title Page

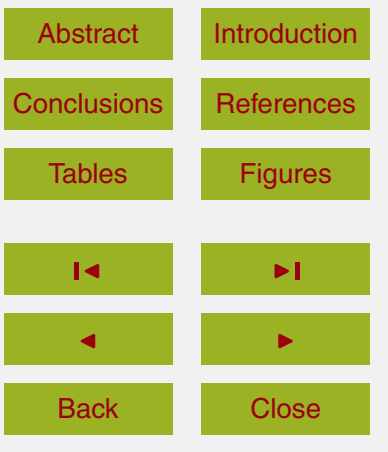

Full Screen / Esc

Printer-friendly Version

Interactive Discussion 
breeding, further differentiated by dry or moist conditions, resulted here in an average yield changes from $-8.2 \%$ to $+38.6 \%$.

Furthermore Buttlar et al. (2013) took a closer look at a part of LS, the region connecting the cities of Hanover, Brunswick, Göttingen and Hildesheim. This study was 5 however rather site specific, with biomass yield changes of maize between $-3 \%$ and $+7 \%$ (until mid-century) and $-4 \%$ to $+13 \%$ (end of century).

While the current study does not expect to diverge largely from these findings, a regional or even local approach was necessary as a probable basis for action of regional decision makers. An important difference to the mentioned studies lies however in the selection of different maize varieties. For simplification many studies omit the use of different varieties that are differentiated only by their required temperature sums to reach their respective development stages. As Southworth et al. (2000) could show in a study in the Midwestern United States this differentiation can indeed make a difference, as heat-resistant late (or long-term) varieties did show a considerably better yield development in a future climate than varieties with less temperature requirements. However rare, if studies do evaluate distinct varieties, the findings are similar as Liu et al. (2013) could show for Northeast China. Most studies however only hint in a more general way towards the influence of variety choice (Wolf and van Diepen, 1994; Kwabiah, 2004; Meza et al., 2008).

The basic approach used in this study was to use high-resolution climate data in combination with detailed soil information as the input for a crop model. All components involved are introduced in the following sections.
BGD

$11,9103-9134,2014$

Maize yield

development in

Lower Saxony

J. F. Degener and

M. Kappas

Title Page

Abstract

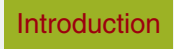

Conclusions

Tables

References

Figures

14

$\rightarrow 1$

$\triangleleft$

$\rightarrow$

Back

Close

Full Screen / Esc

Printer-friendly Version

Interactive Discussion 


\subsection{Research area}

25

Lower Saxony (LS), with roughly $46500 \mathrm{~km}^{2}$ of land area, is the second largest of the 16 federal states of Germany, providing around $15 \%$ of the nations agricultural land (DeStatis, 2013). Located to the North-West of Germany (Fig. 1) the state lies in a transition zone between a more maritime (NW) towards a more continental climate (SE) (Seedorf and Meyer, 1992) with an average annual temperature of around $9^{\circ} \mathrm{C}$ 5 and a mean precipitation of $749 \mathrm{~mm}$ in the period of 1971-2000 (DWD, 2014).

Principally LS consists of three distinguishable landscape structures: the coast, including the East Frisian Islands, the German North-Western Lowland (amounting for three quarters of LS' total land area) as well as a low mountain range to its south, with the Harz as its most prominent representative (Drachenfels, 2010). The broad loess valleys to the south and especially the fertile "Börde" that fronts the low mountain range to the north are the main cultivation areas for high-demand crops like winter wheat. The Lowland mainly consists of "Geest"-land, Quaternary sediments that are particularly sandy to the North-East, with precipitation as low as $500 \mathrm{~mm}$, making irrigation already today necessary on several sites. The west of LS is dominated by

15 livestock farming with the coastal area predominantly used for grassland farming as high ground water levels prevent intensive use (Heunisch et al., 2007).

The regional differences manifest themselves in the average regional yields. In the period of 2003-2008 the average winter wheat yield south of Hanover was always above $8 \mathrm{tha}^{-1}$, above $7 \mathrm{tha}^{-1}$ south of Oldenburg and generally below $7 \mathrm{tha}^{-1}$ in the
North-East. Maize yields behave rather similar, with dry maize silage (33\% dry matter content) having the best yields to the south. The margin between the different parts of LS is however smaller for maize than for wheat and varies generally around $15 \mathrm{tha}^{-1}$. As can be seen in Fig. 1 the areas with the largest maize production coincide with areas where only little wheat is grown and where feed for livestock is in high demand.
BGD

$11,9103-9134,2014$

Maize yield

development in

Lower Saxony

J. F. Degener and

M. Kappas

Title Page

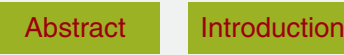

Conclusions References

Tables

Figures

14

$\rightarrow 1$

$\triangleleft$

Back

Close

Printer-friendly Version

Interactive Discussion 
The crop model used in this study is a relatively new model called BioSTAR, developed at the Georg-August-University in Göttingen (Bauböck, 2013). The model uses a $\mathrm{CO}_{2}$ based crop development engine, thus taking a potential $\mathrm{CO}_{2}$ fertilization effect into account.

The basic working principle uses temperature to determine the plants development stages and a combination of temperature, solar radiation and $\mathrm{CO}_{2}$ concentration the maximum photosynthesis rate. Both incrementally build the plants maximum possible 5 biomass that is then limited by precipitation respectively the soil water content. The model is suitable for large-scale as well as parcel size yield assessments. The philosophy behind it is an easy to use model with a robust output and a manageable amount of required input parameters.

The model was validated on sample sites in Lower Saxony with a general disagreement between actual and modeled yield of around $10 \%$. The required climatic input variables are precipitation, temperature, atmospheric $\mathrm{CO}_{2}$ concentration, solar radiation, relative air humidity and wind-speed at $2 \mathrm{~m}$ altitude. In addition, information on the soil type is required. As the model was initially conceived as a tool for the estimation of bio-energy potentials, the maize crops only contain silage maize (no food maize). Furthermore the three varieties do not consist of single breeds but represent an average of several early, medium or late breeds respectively.

As a rather robust approach the model leaves out some aspects that might well be of great importance for a future yield development. Results in this study should thus be read as what would happen if nothing but the climatic input variables would change. 20 These neglected aspects include any technological advances, including any changes in farm management. Irrigation was not included in the modeling, whether for current nor future yields, even if there do exist some areas today that are under irrigation. The sowing date was always the 115th day of the year and was not changed throughout the century. No extra fertilization was included and soil water content expected to be at

Maize yield development in Lower Saxony

J. F. Degener and

M. Kappas

Title Page

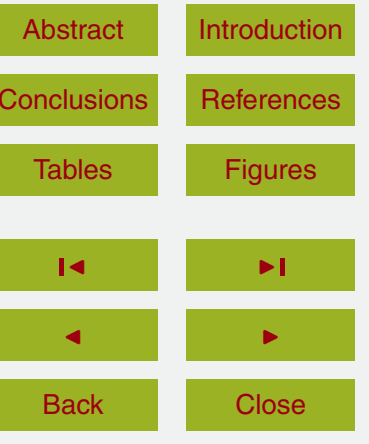

Full Screen / Esc

Printer-friendly Version

Interactive Discussion 
$25100 \%$ at the beginning of the growing season. No effects of a prior crop on a specific site are taken into account. The model either stopped on day 300 of a given year or when full maturity was attained, depending on what happened first.

At the time of the actual modeling the BioSTAR model could be understood as being in beta stage development. All crops had been validated, however some minor changes in the model engine and more heavy changes in the programs layout have happened since. No version number was in use when the model was applied.

The soil data used in this study is part of the official digital soil survey map of LS in a resolution of $1: 50000$, called BÜK 50 (Boess et al., 2004). This map was intersected with data from the CORINE land-use classification of 2005 for Lower Saxony to extract sites that are used for agricultural purposes only. The result between the intersected soil and land-use map was a data-set of 91014 sites with each used a as unique modeling area. The soil map contained codified information on the soil type and its thickness that were translated into the format required by BioSTAR. Fifteen $10 \mathrm{~cm}$ soil levels had to be identified, each containing the information on prevalent soil type with a 16th level representing everything below the initial $1.5 \mathrm{~m}$. The crop model uses these

\subsection{Climate model and data}

The climate data was derived from the regional climate model WETTREG, a German portmanteau word translating into "weather condition based regional model". The model uses a statistical downscaling method where large scale atmospheric patterns are brought into a statistical relationship with local climate station data (Enke and Spekat, 1997). The initial link is created by using known measured data at these stations and globally gridded reanalysis data, with both ERA 40 and NCEP/NCAR data using a k-means cluster approach. This link is then reestablished through GCM de-
BGD

11, 9103-9134, 2014

Maize yield

development in

Lower Saxony

J. F. Degener and

M. Kappas

Title Page

Abstract

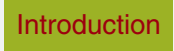

Conclusions

Tables

References

Figures

14

I

4

Back

Close

Printer-friendly Version

Interactive Discussion 
rived gridded data, here from the ECHAM 5 global climate model. For each large scale pled several times to create the climate signal (Enke et al., 2005).

The actual climate models name is WETTREG 2010, as the initial approach (today called WETTREG 2006) neglected weather patterns that are relatively rare today but will increasingly emerge in a future climate. Thus two patterns were added to this latest version, significantly reducing the model bias in comparison to other climate models (Kreienkamp et al., 2010). WETTREG 2010 was applied at 248 stations dis5 tributed throughout LS, whereas the mean of 10 iterations at each station was used as the climate signal for the 21st century (A1B SRES scenario). Using spatial interpolation methodology these point based information were further upscaled to a grid of $100 \mathrm{~m} \times 100 \mathrm{~m}$ at the Jülich Research Centre through the CLINT interpolation model (Müller et al., 2012). This resulted in a grid of 11520000 data points for each time step (with 10-day-values amounting to 36 single steps per year) for temperature, precipitation and potential evapotranspiration. The data was available for the years 1961-2100 with an additional data-set of interpolated measured station data from Germany's National Meteorological Service (DWD) for the years 1961-2005 for validation purposes. Both data-sets agreed reasonably well in temperature and precipitation (with WET15 TREG 2010 showing a mean annual average bias of $+0.02{ }^{\circ} \mathrm{C}$ and $-2.24 \%$ precipitation).

Furthermore data on global radiation was taken from a run of ECHAM 5 in a global T31 grid of $48 \times 96$ that was calculated within the scope of the ENSEMBLES project (Roeckner, 2009). The ECHAM 5 data was chosen for the purpose of data consistency as the WetTREG2010 data did also employ ECHAM 5 runs for the boundary conditions. The data-set was provided for the years 2001 until 2099 thus setting the limits for this study's timeframe. Global radiation was calculated as the sum of surface net downward shortwave flux and surface net downward longwave flux.

Wind speed was taken from official maps of LS of 2005 provided through the State
BGD

$11,9103-9134,2014$

Maize yield

development in

Lower Saxony

J. F. Degener and

M. Kappas

Title Page

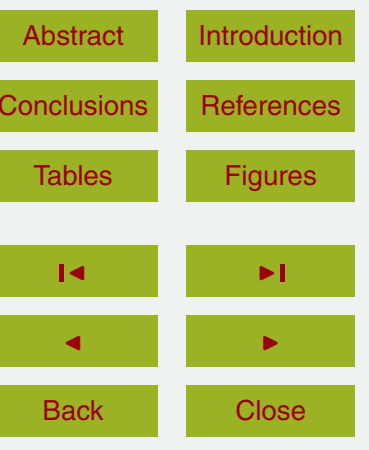

Full Screen / Esc

Printer-friendly Version

Interactive Discussion 
speed in a height of $2 \mathrm{~m}$ above grass. Typical wind-speed ranges from $5-6 \mathrm{~m} \mathrm{~s}^{-1}$ at the coast to around $1-2 \mathrm{~m} \mathrm{~s}^{-1}$ in the south of LS. To present knowledge no significant change in the wind speed pattern is anticipated for the future (NMUEK, 2012), hence the data was applied without further changes.

Relative Air Humidity was calculated backwards from the WETTREG2010 data on evapotranspiration, as this was derived through the Penman/Monteith approach.

All data was then intersected with the soil sites using the respective variables mean 5 value.

\subsection{Statistics}

To account for extreme or unrealistic outliers, a two-way approach was devised for the original resulting data-set. At first all sites with a biomass yield of $0 \mathrm{~g} \mathrm{~m}^{-2}$ were excluded. This typically amounted to 706 sites that contain only bedrock in their soil levels. In a second step all data below the 0.1 and above the 99.9 percentile were excluded, as values close to zero or unreasonably large yields were present. This proved to well eliminate outliers while preserving as much data as possible.

Basic statistics in this study include standard deviation, coefficient of variability (cov), linear regression models and the coefficient of determination as described in Schönwiese (2006). The time series could well be described using linear regression models, however tests with exponential, logarithmic, second and third order polynomial and potential models did show about equal results.

The data was further explicitly tested for trends using a robust trend/noise ratio $(t / n)$, where the difference in yield from the years 2099 and 2001 was divided through the 20 time series' standard deviation. A significant trend is assumed at a ratio of 1.96 or above, representing the $\alpha=0.05$ level. As this test is often considered to be relatively weak, the non-parametric Mann-Kendall-Test (MK) was applied as well. A further advantage of $\mathrm{MK}$ is its ability to detect non-linear trends. Most statistics were applied for the time series of 2001-2030, 2001-2050 and 2001-2099.
BGD

$11,9103-9134,2014$

Maize yield

development in

Lower Saxony

J. F. Degener and

M. Kappas

Title Page

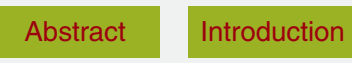

Conclusions References

Tables

Figures

14

I

4

Back

Close

Printer-friendly Version

Interactive Discussion 
25 Data comparing first (2001-2050) and second (2051-2099) half of the century will sometimes give a ratio of $1 \mathrm{st} / 2$ nd half. As the second half is here only 49 years long, only a ratio of 0.505 would mean that the value is equal for both half's.

To determine the climatic variables that significantly influence the yield development throughout the century a multivariate regression model was used. In a first step 11 variables were included in the model that was then run for all sites. These variables include respectively 5 temperature and precipitation values (annual, winter, spring, summer, fall mean) as well as atmospheric $\mathrm{CO}_{2}$ concentration. This was done to get a general test 5 of strength of all variables against each other at different sites. However, autocorrelation is very likely to occur, as at least temperature trends seem to be relatively equal across the five variables. Therefore a best-model approach was devised. 11 variables can be assembled into 2047 unique groups when their order is neglected. Each combination was treated as a new model and calculated on 3740 randomly distributed sites.

10 The multivariate model that explained the yield development best was then logged. If combinations gave equally good results, the first run, generally the one with less variables, was logged. This was done for the years 2001-2099 as well as 2001-2050 to identify possible changes in variable impact.

The statistics in this study have been calculated using MS Excel 2010 and Python 15 (v2.7) with the addition of ScIPY and NumPY (Jones et al., 2001-), Pandas (Pandas, 2012) and MATPLOTLIB (Hunter, 2007). The calculation of the multivariate regression models was done using $R$ ( $v 2.15 .2)$ and $r p y 2$ ( $v 2.3 .0)$.

\section{Climate change in Lower Saxony}

Figure 2 gives a brief description of the average change of the climatic variables temperature and precipitation in LS. The climatic comparison is done by 30 -year intervals where 1971-2000 is used as present-day climate that might be seen as more current than the climatic normal period of 1961-1990 (WMO, 2011). These intervals represent
BGD

11, 9103-9134, 2014

Maize yield

development in

Lower Saxony

J. F. Degener and

M. Kappas

Title Page

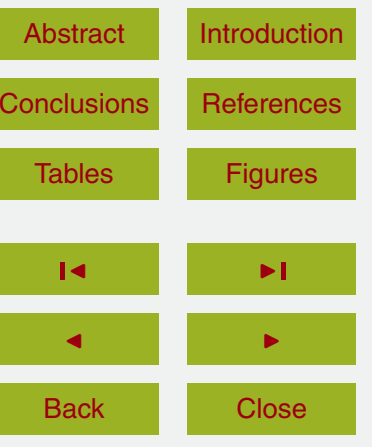

Full Screen / Esc

Printer-friendly Version

Interactive Discussion 
a near (2011-2040), middle (2041-2070) and long-term (2071-2100) climatic development.

25 There are no areas at any time that do show a stagnant or even decreasing temperature development. However, warming in spring is always below the annual average while the winter months are always above. Fall temperatures are slightly below annual average and summer months above, though both deviate less from the mean than spring and winter seasons do. The mean temperature increase is $0.95^{\circ} \mathrm{C}$ for near, $2.30^{\circ} \mathrm{C}$ for middle and $3.40^{\circ} \mathrm{C}$ for long-term scenarios. The development is relatively

5 uniform throughout LS with a slightly stronger (but still less than $0.5^{\circ} \mathrm{C}$ difference) development to the south-east.

The precipitation development is different in terms of being positive or negative depending on time and space. If only annual means are considered, almost no change in precipitation can be detected, although a moderate decline is visible. It however becomes increasingly obvious that the winter and summer seasons are drifting into opposite directions. While in the near future all seasonal differences remain in a window of more or less $\pm 10 \%$, these changes drastically amplify towards the end. The mean decline in precipitation is around $-25 \%$ in the long-term perspective with some areas at a nearly $-50 \%$ decrease. Winter increases are also substantial but at around $1515 \%$ towards the end of the century they cannot fully counterbalance the summery losses.

In summary, all deviations from today's values will increase with passing time, fostering a local development towards a more winter rain climate that features increasingly hot and dry summers and mild wet winters.

\section{Results}

The results in this study will describe the change in biomass yields during the 21st century. Changes are relative to the mean yields of the decade 2001-2010 as a representation of the present time.

Maize yield development in

Lower Saxony

J. F. Degener and

M. Kappas

Title Page

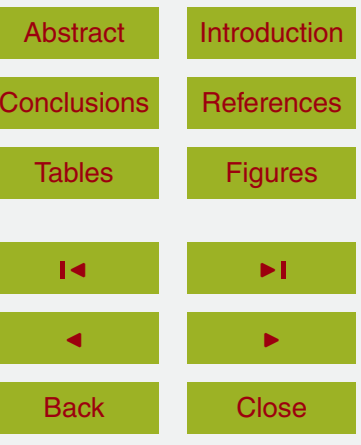

Full Screen / Esc

Printer-friendly Version

Interactive Discussion 


\subsection{Mean yield development}

25 The results in this section give the average yield development of all modeled sites. As can be seen in Fig. 3 all three varieties visually show a positive yield development throughout the century. This is further underpinned by the actual biomass yields after 2060, where the average yield per decade is always higher than for the reference period. Not as evident is the shared pattern of the decadic coefficient of variability. All 5 three varieties have their lowest value in the present (3-4\%) with an increase (except for the comparably low variability between 2031-2040) towards mid-century (above $8 \%$ ) and a slight decline towards $6-7 \%$ at the end of the century. Actual yields will therefore vary more widely around the decadic mean at mid-century.

Apart from these shared aspects there are also obvious differences in the overall 10 development. The following description will thus cover each variety on its own.

The early variety shows an $R^{2}=0.24$ and an average increase in yields of $0.12 \%$ p.a. throughout the century. This trend could be slightly better explained through a polynomial model of second or third order with $R^{2}=0.27$, however no big advantage would be expected from such an approach. The trend/noise $(t / n)$ ratio 1.68 shows no sig15 nificant trend for $\alpha=0.95$ but would for $\alpha=0.9$. Mann-Kendall delivers a more unambiguous result with $p<0.001$ over the century. It is therefore assumed that a significant trend exists throughout the entire time-period.

This trend can basically be split into two parts: the period 2001-2050 has an $R^{2}=$ 0.003 in a linear regression model with an average yield development of $\pm 0 \%$ p.a. 20 The period 2051-2099 has an $R^{2}=0.11$ with an average yield increase of $0.2 \%$ p.a. The lack of a trend in the first half of the century is confirmed by its $t / n$ ratio of 0.5 and $p=0.39$ for MK. For the period 2001-2030 there even seems to appear a slight negative development, with a $t / n$ ratio of -0.63 and a $p=0.08$ for MK that is however not recognized as being significant.

25 All in all it seems clear that a change in biomass yields is expected to happen, however only after the mid of the century and especially after 2070 when there is only
BGD

$11,9103-9134,2014$

Maize yield

development in

Lower Saxony

J. F. Degener and

M. Kappas

Title Page

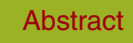

Introduction

Conclusions

Tables

References

Figures

14

$\rightarrow 1$

$\triangleleft$

Back

Close

Printer-friendly Version

Interactive Discussion 
one year with a critically lower yield than the present average. In these last thirty years the yields are about $9 \%$ higher than in the first decade, with the last decade being the one with the overall highest yields. If total production of early maize would be calculated over the century, $49.1 \%$ would be produced during the first half.

The medium variety has an $R^{2}=0.15$ and an average increase in yields of $0.09 \%$ p.a. over the century. As with the early variety a slightly better explanation is provided through a polynomial model with $R^{2}=0.19$. A $t / n$ ratio of 1.34 indicates no linear 5 trend while a $p<0.001$ for MK assumes a significant trend. These numbers represent the lowest indicator for a trend throughout the century of all varieties.

This is due to a different break within the data that occurs around 2030 and is still present when the year is shifted \pm 10 , though weaker. The period 2001-2030 shows a linear decline in yields of around $-0.2 \%$ p.a. and an $R^{2}=0.16$. From 2031 on this 0 turns towards a positive trend of $+0.13 \%$ p.a. and an $R^{2}=0.14$. While the early variety did also show signs for a decline in yields, the data for the medium variety supports it more strongly. While a $t / n$ ratio of -1.3 fails to be significant, the MK with $p=0.005$ is, therefore a significant negative trend until 2030 is assumed. On average this decline will reduce the yields about $5 \%$.

15 This trend is then reversed towards the end of the century, in such a way that around 2070 the yields are mostly above the present average. However, this happens in a lower magnitude than for the early variety. If only the period 2001-2050 is considered, $t / n$ (0.01) and MK $(p=0.95)$ are both highly insignificant, meaning that the average yields are not changing. As this is generally comparable to the early variety, the yield variability is somewhat larger for the medium variety.

The medium variety will thus have the least positive development in the 21st century. Yields after 2070 will on average be $5 \%$ above today's. A comparison of both half's of the century has $49.4 \%$ of a potential production happen in the first 50 years, again the highest value of all varieties.

25 The late variety is somewhat of an exception. Where early and medium variety show at least minor comparability, the late variety has a uniquely positive development path.
BGD

$11,9103-9134,2014$

Maize yield

development in

Lower Saxony

J. F. Degener and

M. Kappas

Title Page

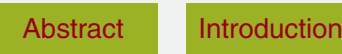

Conclusions References

Tables

Figures

14

$\rightarrow 1$

4

Back

Close

Printer-friendly Version

Interactive Discussion 
This is evident by just looking at the graph as well as in the numbers of the linear regression model with an $R^{2}=0.65$ and an average yield increase of $0.31 \%$ p.a. A change to another regression model does not show any different results. Also the $t / n$ ratio $(2.74)$ and Mann-Kendall $(p<0.001)$ are more explicit in determining significance than for the other varieties.

However clear, this trend is not entirely constant. While the $t / n$ ratio (2.31) and MK $(p<0.001)$ already show a highly significant trend towards 2050 the data seems to 5 have a break around the year 2030. There appears to be no trend for the period 20012030 as a $t / n$ ratio of 0.65 and $p=0.35$ for MK suggest. A linear regression for 20012030 shows an $R^{2}=0.09$ and a mean yield increase of $0.11 \%$ p.a., a non-significant but positive trend, whereas 2031-2099 has a $R^{2}=0.37$ and an increase of $0.26 \%$ p.a.

The late variety has thus the most positive development throughout the century. The 10 mean yields in the last three decades increase about at least $10 \%$ compared to today, with a mean of $25 \%$ and a maximum of $36 \%$. The same holds true for a production comparison of both half-centuries, as the first 50 years would only contribute $47.1 \%$ to a potential overall production.

\subsection{Regional yield development}

15 As Fig. 4 indicates there are also certain differences in the regional distribution of potential yields increases or decreases. The late variety does clearly have the most uniform development as it is positive for almost all times and sites. The share of sites with a positive development lies around $53 \%$ for the early variety in the period and increases to $87 \%, 96 \%$ and $95 \%$ towards the end of the century. In a similar fashion the medium variety starts out at very low share of $16 \%$ positive sites, increasing to $49 \%, 88 \%$ and $83 \%$.

If the coefficient of variation is calculated regarding all sites and years from the respective periods, all three varieties show an increasing cov with progressing time. With $9.3 \%(2021-2040)$ to $10.7 \%(2081-2099)$ the late variety does have the least variabil- 

variation in their yields.

The overall best sites are situated in the west of LS. Two main areas with a belowaverage yield development can be identified. One is to the north or north-east of LS, the other one to the south. This southern area is however not affected uniformly but rather quite positive and quite negative sites are alternating. The negative sites are consistently those with an overall shallow profile, situated on the slopes of the hilly

5 landscape. By contrast, the sites with a positive development lie within the fertile river valleys with their good soil quality.

Good soil quality is here defined only through the soils ability to retain water, basically defined by its field capacity.

\subsection{Process analysis}

10 To determine the relative influence of certain variables on crop growth, a multivariate linear regression model was applied with the results shown in Fig. 5. On the left side single parameters are tested against each other for their quantitative and qualitative input strength. For example, a positive correlation of +4 for medium maize and $\mathrm{CO}_{2}$ indicates that a rise in atmospheric $\mathrm{CO}_{2}$ concentrations by $1 \mathrm{ppm}$ leads to a yield in-

15 crease of $4 \mathrm{~g} \mathrm{~m}^{-2}$. A negative correlation, as for example for summer temperature and medium variety, would however stand for a decline in yields by roughly $100 \mathrm{~g} \mathrm{~m}^{-2}$ if summer temperatures would rise by $1^{\circ} \mathrm{C}$.

The shown results are the mean output of all sampled sites. Though problems due to some autocorrelation were expected, the linear multivariate models performed quite 20 well. For 2001-2099 the mean model $p$ value over all sites was $<0.001$ for all varieties. For the late variety this holds true not just for the mean but even if all sites are regarded individually. The early and medium varieties did however contain around $1300(1.5 \%)$ sites of less significance, which were however still within a margin of $0.01>p>0.001$. The models concerning the first half of the century, 2001-2050, show slightly worse results. Though the mean $p$ value of all models is still $<0.001$, the number of models

Maize yield development in Lower Saxony

J. F. Degener and

M. Kappas

Title Page

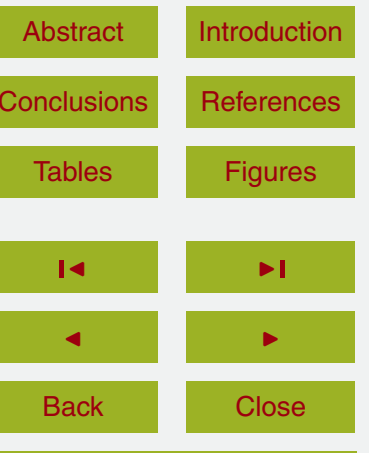

Full Screen / Esc

Printer-friendly Version

Interactive Discussion 
with higher $p$ values increased. Even the late variety now did have around 1500 sites exceeding this threshold, with early and medium variety on about 7000 sites. Roughly a third of these exceptional sites have $p$ values $>0.05$. In conclusion, the models are slightly better for the description of the long-term development than for the first half of the century.

For 2001-2099 two main influence variables are detected. Summer precipitation shows a strong positive correlation for all three varieties. As the amount of rain is ex-

5 pected to drastically decline throughout the century, this seems to be the main factor to limit future maize yields. On the other hand, atmospheric $\mathrm{CO}_{2}$ concentrations have a comparable positive correlation and are thus possibly the main agent for a positive yield development. The amount of spring precipitation seems to be of higher importance for medium $(p=0.09)$ and especially early $(p=0.04)$ variety. Both do also show

10 a negative connection with the rising summer temperatures (early $p=0.09$, medium $p=0.08$ ), at least to some degree. The late variety shows basically similar dependencies, however weaker. Instead spring temperatures $(p<0.01)$ seem to be of much higher importance than for the other two varieties.

For 2001-2050 these indicators change only slightly. Still summer precipitation and $\mathrm{CO}_{2}$ concentrations remain the determining variables $(p<0.001)$. The late variety still shows some dependency towards spring temperatures $(p=0.09)$. For all three varieties fall temperatures seem to be of higher importance in the first 50 years $(0.1>p>0.05)$, whereas summer temperatures and spring precipitation have no apparent influence.

20 That these multivariate models are not entirely perfect becomes evident when for example winter precipitation and late maize are considered for 2001-2099. While not being highly significant a certain connection between both variables is suggested. However, as winter months include December, January and February, when no maize is grown, this also seems to be highly improbable. While the statistical model was be25 lieved to be reasonably good in determining the relative influence of each variable, there was a need to exclude variables that are not necessarily important.

BGD

$11,9103-9134,2014$

Maize yield development in Lower Saxony

J. F. Degener and

M. Kappas

Title Page

Abstract Introduction

Conclusions

Tables References Figures

14 $\rightarrow 1$

4

Back

Close

Printer-friendly Version

Interactive Discussion 
Therefore the next step was to identify the one linear multivariate regression model for each site that best describes its yield development, as shown on the right side in Fig. 5. These results were largely in accordance with the results from the models with eleven input variables. Models in the following approach are numbered from R1 to R2047. $\mathrm{R}$ is here short for Run while the number indicates the variable combination. Higher numbers relate to more input variables. The relevant numbers are explained further in Fig. 5.

For 2001-2099 the model best describing the yield development of all varieties was one containing only summer precipitation and $\mathrm{CO}_{2}$ concentrations (R37). $92 \%$ of the early variety, $80 \%$ of the medium variety and $85 \%$ of the late variety sites had this as the optimal model. The remaining sites of the early variety were best described by a model only containing $\mathrm{CO}_{2}$ concentrations (R10). The same is partially true for the late variety, as $3 \%$ of the models show their best results when only including $\mathrm{CO}_{2}$ (R10), however models that only used spring temperatures (R6) accounted for the remaining $12 \%$. This connection to spring temperatures was also be identified in the models featuring all variables. The two runs R6 and R10 have a combined share of about $10 \%$ of the medium variety's remaining sites, while the other remaining $10 \%$ are a combination of summer precipitation, summer temperatures and $\mathrm{CO}_{2}$ concentration (R171).

For the period 2001-2050 the varieties did show a more differentiated picture. The late variety did still have R37 as the dominant model on $90 \%$ of its sites. $5 \%$ were made up of R6 and another $5 \%$ of other not further distinguished models. The early 20 variety had R37 on just $58 \%$ of its sites, $5 \%$ showing R171 and almost the entire rest of $34 \%$ from R2 with summer precipitation only. The medium variety had only have $24 \%$ comprising of R37, $6 \%$ of R171 and a dominating $66 \%$ of R2.
BGD

$11,9103-9134,2014$

Maize yield

development in

Lower Saxony

J. F. Degener and

M. Kappas

Title Page

Abstract

Introduction

Conclusions

Tables

References

Figures

14

$\rightarrow$ I

4

Back

Close

Printer-friendly Version

Interactive Discussion 


\section{Discussion}

The results from this study basically agree with the findings of e.g. Southworth et al. 25 (2000) in that the choice of variety will have a critical effect on how maize yields will develop under a future climate. It even agrees to the point that late varieties will show the most positive development which can be quite substantial with $>25 \%$ in Lower Saxony towards the end of the century.

One reason for this beneficial development of late maize is clearly the fact that today's temperature sums in LS are not suitable for a full completion of its growing cycle. Temperature sums from 20 April to 15 October (minus $6^{\circ} \mathrm{C}$ temperature basis) vary 5 today around $1500^{\circ} \mathrm{C}$ in LS and are therefore perfect for medium varieties but below optimum for late varieties. It seems that around 2030, when temperature sums have increased by about $100^{\circ} \mathrm{C}$, the late variety can fully benefit from these temperatures. That the late variety disproportionately benefits from the generally rising temperatures is further supported by statistical analysis, as the late variety is the only one to show

10 a substantial positive correlation to rising spring temperatures.

The future climatic condition are however not entirely beneficial for the growth of late maize varieties. The main limiting factor, for all varieties, is the decline in summer precipitation. However, the time spent within these dry months in relation to the total growing time is shorter for the late variety as e.g. the medium one. Thus the late variety can use the moister spring or fall conditions for a successful growth. Similarly the early variety profits from the spring conditions while the medium variety would need more water during the summer months of which August will be the driest.

An adaption of sowing date could mitigate these negative effects to some degree. Some testing on single sites however suggests that the general yield development series of late $>$ early $>$ medium variety is not changed, though the absolute difference might change. The influence of the sowing date on the results of this work are currently under evaluation.

Maize yield development in

Lower Saxony

J. F. Degener and

M. Kappas

Title Page

Abstract Introduction

Conclusions

Tables

References

Figures

14

4

Back

Close

Printer-friendly Version

Interactive Discussion 
In a related matter, critical development stages of maize, e.g. during flowering, where water shortage disproportionately restrains plant growth (Ehlers, 1996), were not sufcurrent version and is under evaluation as well. While a shift in sowing dates is expected to be generally beneficial for maize yields, this increase in sensitivity is believed to have a rather detrimental effect.

While increasing temperatures are generally good for the late variety, temperatures during the growing season should not exceed an optimum growing temperatures of 25$30^{\circ} \mathrm{C}$ over longer time periods, as this would inhibit photosynthesis rates (Endlicher, 2007). However, heat days will increase in LS throughout the century. The effects of this 5 are visible in the multivariate regression models with an increasing negative impact of summer temperatures on yields.

In reality this effect is expected to be even worse. The main reason is the use of a relatively smooth time-series. This is firstly caused by the statistical nature of the climate model. The usage of mean values from 10 climate model runs tends to elim10 inate extreme values. Secondly, the results of this downscaled climate data-set were 10-day-values that were further combined into monthly averages. Temperature peaks were thus eliminated within the monthly means. The same is true for the monthly values of precipitation, as BioSTAR simply assumes that the monthly value is distributed evenly over each day of the month. This is clearly not the case in nature where a steady 15 flow of water would be optimal for the plants water supply. It will make some difference if $20 \mathrm{~mm}$ precipitates in one day followed by nine dry days or if $2 \mathrm{~mm}$ for each of the ten days is assumed. While a shortage in precipitation might be worse than elevated temperatures, it can be mitigated relatively easy by irrigation while the latter can hardly be opposed. As some areas in LS are already today under irrigation it would be interestamount of water needed for optimal growth and taking the actually available amount of water into account.

BGD

$11,9103-9134,2014$

Maize yield

development in

Lower Saxony

J. F. Degener and

M. Kappas

Title Page

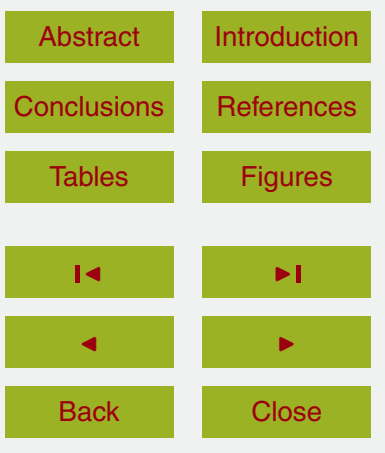

Full Screen / Esc

Printer-friendly Version

Interactive Discussion 
That even relatively smooth precipitation series lead to varying yields becomes evident when the observed decadic variability of the yields is compared with the variability of precipitation. More precisely the yields have their greatest variability in the decade 2051-2060, when summer precipitation has the greatest variability too. The same link can be found in the decade 2021-2030 but not for 2031-2050, as both decades have either high yield or high precipitation variability but not both. The underlying cause for the change in yield variability therefore seems to be more complex than a single dependency on summer precipitation.

There further exist some climatic circumstances that might negatively affect yield development that were not accounted for in this study. One is tropospheric ozone, as $30 \mathrm{ppb}$ are sufficient to induce ozone intoxication in plants (Long et al., 2006). Since 51950 the concentration of tropospheric ozone has nearly doubled. Studies suggest that maize yields might be $2-5.5 \%$ higher today if this rise would not have happened (Avnery et al., 2011). It is however debatable if tropospheric ozone concentrations will further increase, at least in Europe, due to anthropogenic emission as CMIP 5 runs suggest (Fiore et al., 2012).

10 A greater potential risk arises through common or invasive pests. Complicated interactions and feedbacks between climate, crop and pests make concise predictions difficult (Schaller and Weigel, 2007). However, as Fröhlich (2010) points out, there is no expectation at all that the climatic change will lead to a reduction in infestation of any pest. In how far new cropping techniques or breeds will be able to counteract such 15 problems is beyond the scope of this study.

The general outlook considering the climatic changes could thus be interpreted as quite severe. However, the results from this study suggest the contrary with rising yields towards the century's end. The only variable contributing significantly towards rising yields is atmospheric $\mathrm{CO}_{2}$.

20 Maize as a $\mathrm{C} 4$ crop is not expected to profit from rising $\mathrm{CO}_{2}$ through an elevated photosynthesis rate (Lambers et al., 2008). However an increased water use efficiency is expected in C3 as well as C4 plants. This effect is accounted for by the crop model,
BGD

11, 9103-9134, 2014

Maize yield

development in

Lower Saxony

J. F. Degener and

M. Kappas

Title Page

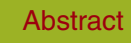

Introduction

Conclusions

Tables

References

Figures

14

$\rightarrow 1$

$\triangleleft$

Back

Close

Printer-friendly Version

Interactive Discussion 
resulting in a relatively linear decrease in the amount of water that is needed to produce the same amount of plant matter. The reduction is comparable for all three varieties and ranges between $25-30 \%$.

In an environment where water is getting increasingly scarce this is a desirable development. It appears that the negative impacts of summer temperature and precipitation are stronger until mid-century, especially for medium or early variety. The positive influence of $\mathrm{CO}_{2}$ steadily increases to a point where the positive effects prevail and yields are rising.

That water saving through increased $\mathrm{CO}_{2}$ concentrations can have such a strong effect is also pointed out by Taube and Herrmann (2009), where Grasslands profit from 5 a rise even under increasing drought stress during summer months. This would be in line with Morgan et al. (2004) who are emphasizing the importance of water saving through increased $\mathrm{CO}_{2}$ in contrast to a direct fertilization effect.

$\mathrm{CO}_{2}$ might still not be solely responsible for the rising yields. It undoubtedly plays a major role in doing so, however other factors that have not been included in the pro10 cess evaluation might contribute as well. Mera et al. (2006) included the effect of solar radiation in their research and found a non-linear contribution to yield development, however not as prominent as changes in precipitation or water availability.

\section{Conclusions}

As could be shown, the changing climate will have a predominantly positive effect on 15 the yield development of maize and its varieties in Lower Saxony. A real positive development is however not expected to set in before the second half of the 21st century.

The first half will be stagnant in yields for the early variety. In the last decades of the century the yields will on average increase about $9 \%$. The medium variety even shows a negative development in the first half that is later reversed. Towards the century's end the yields then increase about $5 \%$ in comparison to today's yields. The late variety has the all-out best yield development, with an average increase of $25 \%$ for 2071-
BGD

$11,9103-9134,2014$

Maize yield

development in

Lower Saxony

J. F. Degener and

M. Kappas

Title Page

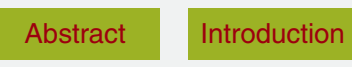

Conclusions References

Tables Figures

14

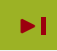

4

Back

Close

Full Screen / Esc

Printer-friendly Version

Interactive Discussion 
2099 and a strong positive trend beginning already around 2030. In addition to this above-average rise the yields itself are higher so that a transition of local agricultural practices towards the late variety is conceivable. The yield development of all yields 25 is accompanied by an increase in yield variability during mid-century that seems to partially follow precipitation patterns.

Thus the development will generally be positive in the long run, though the path for each variety diverges. As the varieties react in different ways to the changing annual pattern of temperature and precipitation, the results do indicate that the consideration of different varieties might also change the outcome of studies at different study sites.

5 At any rate the few other existing studies are hinting towards the same result. Varieties with longer or shorter growing periods will have an advantage in areas where medium varieties are predominantly grown today.

Besides, for Lower Saxony or Germany in general, a decline in summer precipitation is not seen as an insurmountable obstacle for local agriculture, as there is no necessity 10 for irrigation on most sites today and present water reserves would allow an expansion of irrigated areas at least to some degree. Intensive groundwater management will a basis for this, as increasing winter precipitation could cover the water extraction during the summer months. New breeds and cropping techniques will also aid to counteract the negative effects of climate change, including the expansion of pests or 15 hitherto unknown effects that might arise.

In conclusion the maize yields in Lower Saxony will not suffer from long lasting declines but will have a generally positive outlook over the course of the 21 st century.

Acknowledgements. We acknowledge support by the Open Access Publication Funds of the Göttingen University. We would like to thank the LBEG for the provision of the climate data-set.

This Open Access Publication is funded by the University of Göttingen.
BGD

$11,9103-9134,2014$

Maize yield

development in

Lower Saxony

J. F. Degener and

M. Kappas

Title Page

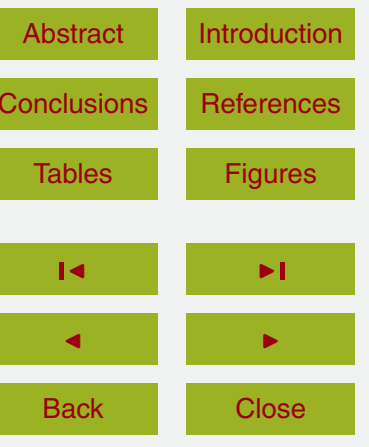

Full Screen / Esc

Printer-friendly Version

Interactive Discussion 


\section{References}

Avnery, S., Mauzerall, D. L., Liu, J., and Horowitz, L. W.: Global crop yield reductions due to surface ozone exposure: 1 . Year 2000 crop production losses and economic damage, Atmos. Environ., 45, 2284-2296, 2011.

25 Bauböck, R.: GIS-aided modeling and analysis of biomass potentials in Lower Saxony - introduction to the crop model BioSTAR, Ph.D. thesis, Georg-August-University, Göttingen, 2013.

Boess, J., Gehrt, E., Müller, U., Ostmann, U., Sbresny, J., and Steininger, A.: Erläuterungsheft zur digitalen nutzungsdifferenzierten Bodenkundlichen Übersichtskarte 1:50.000 (BÜK50n) von Niedersachsen, vol. 3 of Arbeitshefte Boden, Hannover, 2004.

Buttlar, C. v., Karpenstein-Machan, M., and Bauböck, R.: Klimafolgenmanagement durch klimaangepasste Anbaukonzepte für Energiepflanzen in der Metropolregion Hannover-

5 Braunschweig-Göttingen-Hildesheim, Ibidem, 2013.

DeStatis: Statistical Yearbook of Germany 2013, 1 edn., Statistisches Bundesamt, Wiesbaden, 2013.

Drachenfels, O.: Überarbeitung der Naturräumlichen Regionen Niedersachsens, Informationsdienst Naturschutz Niedersachsen, 30, 249-252, available at: http://www.nlwkn. niedersachsen.de/download/54126, (last access: 17 July 2013), 2010.

DWD: Website of the German Weather Service, available at: http://www.dwd.de (last access: 24 March 2014), 2014.

Ehlers, W.: Wasser in Boden und Pflanze: Dynamik des Wasserhaushalts als Grundlage von Pflanzenwachstum und Ertrag, Ulmer (Eugen), 1996.

Endlicher, W. (Ed.): Der Klimawandel: Einblicke, Rückblicke und Ausblicke, Potsdam-Inst. für Klimafolgenforschung, Potsdam, 2007.

Enke, W. and Spekat, A.: Downscaling climate model outputs into local and regional weather elements by classification and regression, Clim. Res., 8, 195-207, 1997.

Enke, W., Deutschlander, T., Schneider, F., and Kuchler, W.: Results of five regional climate studies applying a weather pattern based downscaling method to ECHAM4 climate simulation, Meteorol. Z., 14, 247-257, 2005.

FAO: FAO online statistical database, available at: http://faostat3.fao.org (last access: 04 February 2014), 2014.
BGD

11, 9103-9134, 2014

Maize yield

development in

Lower Saxony

J. F. Degener and

M. Kappas

Title Page

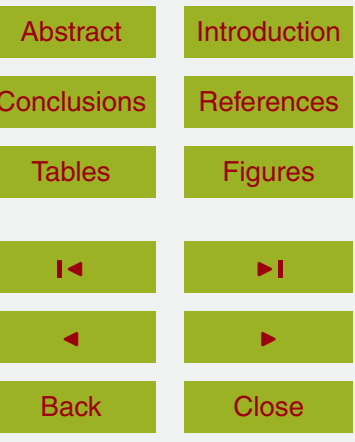

Full Screen / Esc

Printer-friendly Version

Interactive Discussion 
Fiore, A. M., Naik, V., Spracklen, D. V., Steiner, A., Unger, N., Prather, M., Bergmann, D.,

Cameron-Smith, P. J., Cionni, I., Collins, W. J., Dalsøren, S., Eyring, V., Folberth, G. A., Ginoux, P., Horowitz, L. W., Josse, B., Lamarque, J.-F., MacKenzie, I. A., Nagashima, T., O’Connor, F. M., Righi, M., Rumbold, S. T., Shindell, D. T., Skeie, R. B., Sudo, K., Szopa, S., Takemura, T., and Zeng, G.: Global air quality and climate, Chem. Soc. Rev., 41, 6663-6683, 2012.

30 Fröhlich, M.: Klimawandel und Landwirtschaft: Auswirkungen der globalen Erwärmung auf die Entwicklung der Pflanzenproduktion in Nordrhein-Westfalen, Ministerium für Klimaschutz, Umwelt, Landwirtschaft, Natur- und Verbraucherschutz des Landes Nordrhein-Westfalen, 2010.

Heunisch, C., Caspers, G., Elbracht, J., Langer, A., Röhling, H.-G., Schwarz, C., and Streif, H.: Erdgeschichte von Niedersachsen: Geologie und Landschaftsentwicklung, Landesamt für Bergbau, Energie und Geologie (LBEG), Hannover, Geoberichte 6, 2007.

Hoeher, G.: Entwicklung Energiepflanzenanbau und Biogas in Niedersachsen, available at: www.ifeu.org/landwirtschaft/pdf/6_Hoeher_Maisanbau_Nieders.pdf, (11 March 2014), 2007.

Hunter, J. D.: Matplotlib: a 2D graphics environment, Comput. Sci. Eng., 9, 90-95, 2007.

Jacob, D., Göttel, H., Kotlarski, S., Lorenz, P., and Sieck, K.: Klimaauswirkungen und Anpassung in Deutschland: Phase 1: Erstellung regionaler Klimaszenarien für Deutschland, Im Auftrag des Umweltbundesamtes, Dessau-Roßlau, Climate Change (11/2008), 2008.

Jones, E., Oliphant, T., Peterson, P., et al.: SciPy: open source scientific tools for Python, (17.07.2013), 2001.

Kreienkamp, F., Spekat, A., and Enke, W.: Weiterentwicklung von WETTREG bezüglich neuartiger Wetterlagen, 2010.

Kwabiah, A.: Growth and yield of sweet corn (Zea mays L.) cultivars in response to planting date and plastic mulch in a short-season environment, Sci. Hortic., 102, 147-166, 2004.

Lambers, H., Pons, T. L., and Chapin, F. S.: Plant Physiological Ecology, 2. edn., Springer, New York, 2008.

Liu, Z., Hubbard, K. G., Lin, X., and Yang, X.: Negative effects of climate warming on maize 20 yield are reversed by the changing of sowing date and cultivar selection in Northeast China, Glob. Change Biol., 19, 3481-3492, 2013.
BGD

11, 9103-9134, 2014

Maize yield

development in

Lower Saxony

J. F. Degener and

M. Kappas

Title Page

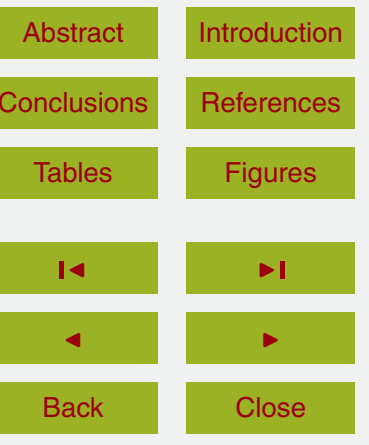

Full Screen / Esc

Printer-friendly Version

Interactive Discussion 
Long, S. P., Ainsworth, E. A., Leakey, A. D. B., Nösberger, J., and Ort, D. R.: Food for thought: lower-than-expected crop yield stimulation with rising $\mathrm{CO}_{2}$ concentrations, Science, 312, 1918-1921, 2006.

LSN: Statistical Data of the Statistical Office of Lower Saxony, available at: http://www.nls. niedersachsen.de/ (last access: 14 March 2014), 2014.

LWK: Homepage of the Chamber of Agricultre of Lower Saxony, available at: http://www. Iwk-niedersachsen.de (last access: 10 March 2014), 2014a.

LWK: Energiepflanzenfeldtage: Es muss nicht immer Mais sein, available at: http://www. Iwk-niedersachsen.de/index.cfm/portal/2/nav/74/article/15172.html (last access: 10 March 2014), 2014b.

Mera, R., Niyogi, D., Buol, G., Wilkerson, G., and Semazzi, F.: Potential individual versus simultaneous climate change effects on soybean $\left(\mathrm{C}_{3}\right)$ and maize $\left(\mathrm{C}_{4}\right)$ crops: an agrotechnology model based study, Global Planet. Change, 54, 163-182, 2006.

Meyer, U., Hüther, L., Manderscheid, R., Weigel, H.-J., Lohölter, M., and Schenderlein, A.: Nutritional value of maize 2050, in: Optimierung des Futterwertes von Mais und Maisprodukten, vol. 331 of Landbauforschung/Sonderheft, edited by: Schwarz, F. J., VTI, Braunschweig, 107-114, 2009.

Meza, F. J., Silva, D., and Vigil, H.: Climate change impacts on irrigated maize in Mediterranean climates: Evaluation of double cropping as an emerging adaptation alternative, Agr. Syst., 98, $10 \quad 21-30,2008$.

Mirschel, W., Wenkel, K.-O., Wieland, R., Köstner, B., Albert, E., and Luzi, K.: Auswirkungen des Klimawandels auf die Ertragsleistung ausgewählter landwirtschaftlicher Fruchtarten im Freistaat Sachsen, ZALF, Müncheberg, 2008.

Mirschel, W., Wieland, R., Wenkel, K.-O., Guddat, C., Michel, H., Luzi, K., and Groth, K.: Regionaldifferenzierte Abschätzung der Auswirkungen des Klimawandels auf die Erträge von wichtigen Fruchtarten im Freistaat Thüringen mittels Ertragssimulation mit YIELDSTAT, ZALF, Müncheberg, 2012.

Morgan, J. A., Pataki, D. E., Körner, C., Clark, H., Del Grosso, S. J., Grünzweig, J. M., Knapp, A. K., Mosier, A. R., Newton, P. C. D., Niklaus, P. A., Nippert, J. B., Nowak, R. S., Parton, W. J., Polley, H. W., and Shaw, M. R.: Water relations in grassland and desert ecosystems exposed to elevated atmospheric $\mathrm{CO}_{2}$, Oecologia, 140, 11-25, 2004.

BGD

$11,9103-9134,2014$

Maize yield

development in

Lower Saxony

J. F. Degener and

M. Kappas

Title Page

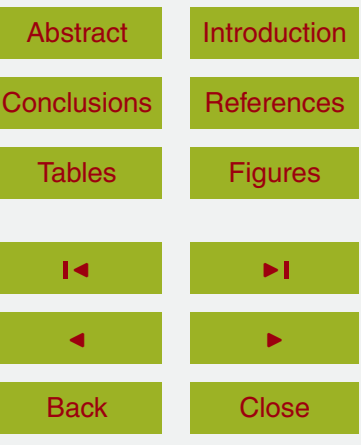

Full Screen / Esc

Printer-friendly Version

Interactive Discussion 
Müller, U., Engel, N., Heidt, L., Schäfer, W., Kunkel, R., Wendland, F., Röhm, H., and Elbracht, J.: Klimawandel und Bodenwasserhaushalt, landesamt für Bergbau, Energie und Geologie (LBEG), Hannover, Geoberichte 20, 2012.

NMELVL: Maisanbau: Mehr Vielfalt durch Alternativen und Blühstreifen, available at: http: //www.ml.niedersachsen.de/download/78012, 2012.

NMUEK: Empfehlung für eine niedersächsische Klimaanpassungsstrategie, 2012.

Pandas: pandas: Python Data Analysis Library, (17.07.2013), 2012.

Roeckner, E.: ensembles stream2 echam5c-mpi-om sra1b run1: World Data Center for Climate, 2009.

Schaller, M. and Weigel, H. J.: Analyse des Sachstands zu Auswirkungen von Klimaveränderungen auf die deutsche Landwirtschaft und Maßnahmen zur Anpassung, 2007.

Schönwiese, C.-D.: Praktische Statistik für Meteorologen und Geowissenschaftler, 4. edn., Borntraeger, Berlin (u.a.), 2006.

Seedorf, H. H. and Meyer, H.-H.: Landeskunde Niedersachsen: Historische Grundlagen und naturräumliche Ausstattung, Wachholtz, Neumünster, 1992.

5 Southworth, J., Randolph, J., Habeck, M., Doering, O., Pfeifer, R., Rao, D., and Johnston, J.: Consequences of future climate change and changing climate variability on maize yields in the midwestern United States, Agr. Ecosyst. Environ., 82, 139-158, 2000.

Supit, I., van Diepen, C., Wit, A. d., Wolf, J., Kabat, P., Baruth, B., and Ludwig, F.: Assessing climate change effects on European crop yields using the Crop Growth Monitoring System and a weather generator, Agr. Forest Meteorol., 164, 96-111, 2012.

Taube, F. and Herrmann, A.: Relative benefit of maize and grass under conditions of climatic change, in: Optimierung des Futterwertes von Mais und Maisprodukten, vol. 331 of Landbauforschung/Sonderheft, edited by: Schwarz, F. J., VTI, Braunschweig, 115-126, 2009.

USF: Klimawandel und Landwirtschaft in Hessen: Mögliche Auswirkungen des Klimawandels auf landwirtschaftliche Erträge, iNKLIM Baustein 2, Universität Kassel, 2005.

WMO: Guide to Climatological Practices: 2011 edition, 2011.

Wolf, J. and van Diepen, C.: Effects of climate change on silage maize production potential in the European community, Agr. Forest Meteorol., 71, 33-60, 1994.

Wolf, J. and van Diepen, C.: Effects of climate change on grain maize yield potential in the european community, Climatic Change, 29, 299-331, 1995. 


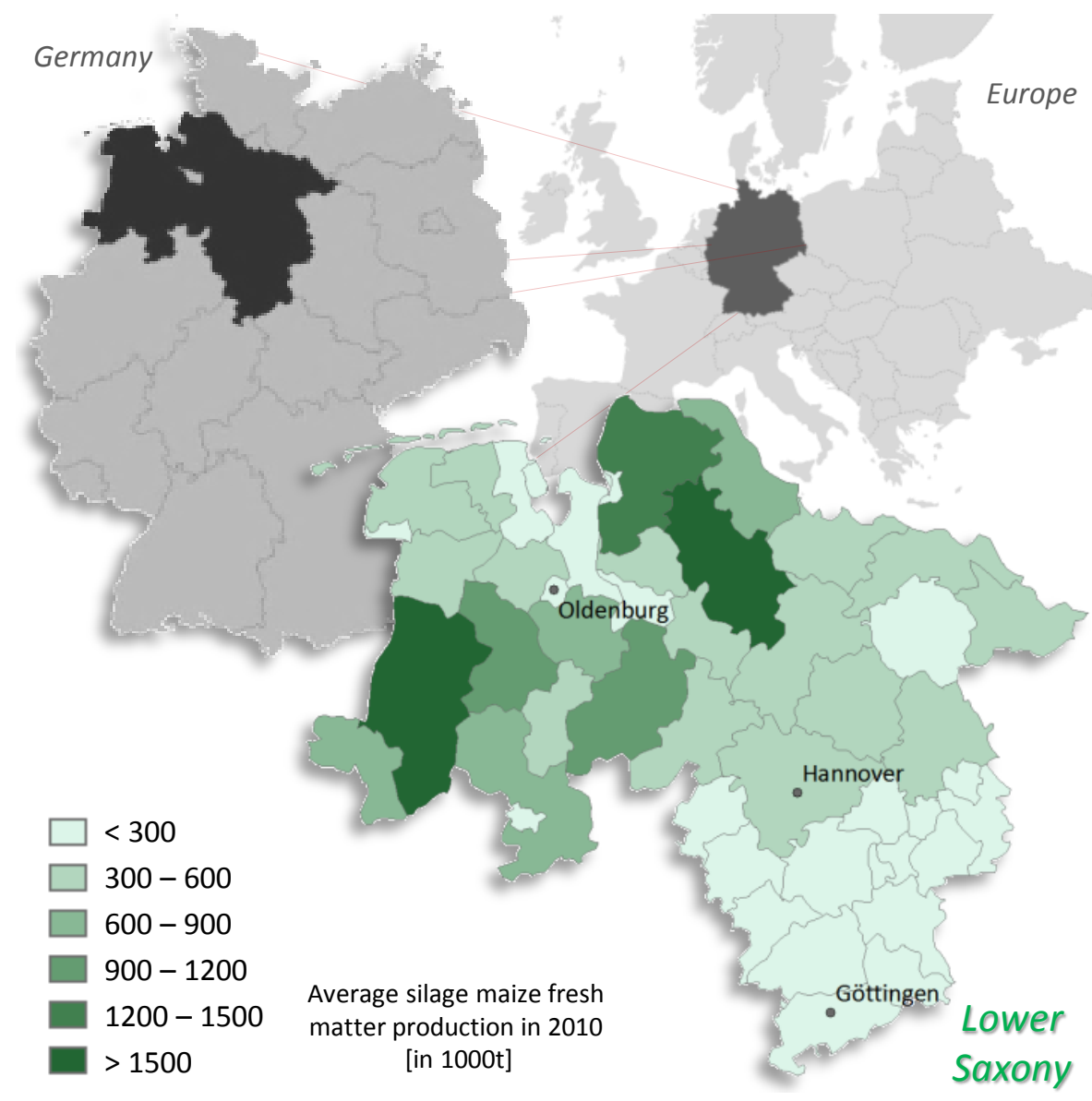

\section{BGD}

11, 9103-9134, 2014

Maize yield development in

Lower Saxony

J. F. Degener and

M. Kappas

Title Page

\begin{tabular}{|c|c|}
\hline Abstract & Introduction \\
\hline Conclusions & References \\
\hline
\end{tabular}

Tables

Figures

14

4

Back

Close

Full Screen / Esc

Printer-friendly Version

Interactive Discussion

Figure 1. Average Maize production in 2010 as fresh-matter in 1000 metric tonnes by district (LSN, 2014). 


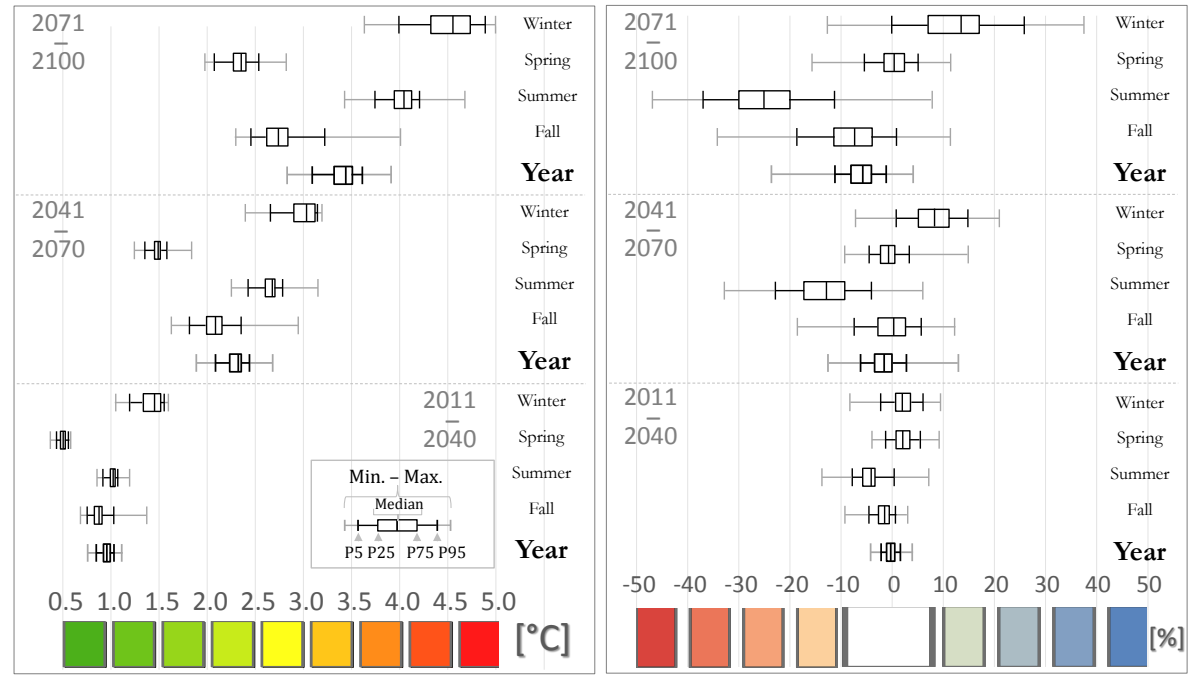

Figure 2. Indicators of a regional climatic change. Box-Whisker-Plots of temperature (left) and precipitation (right) changes for three different periods in relation to 1971-2000 by season. The data is taken from the WETTREG2010 data-set and represents the mean over Lower Saxony.

\section{BGD}

11, 9103-9134, 2014

Maize yield

development in

Lower Saxony

J. F. Degener and

M. Kappas

Title Page

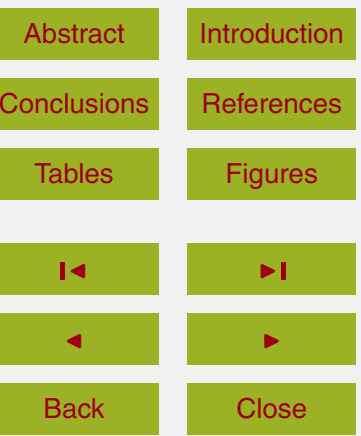

Full Screen / Esc

Printer-friendly Version

Interactive Discussion 

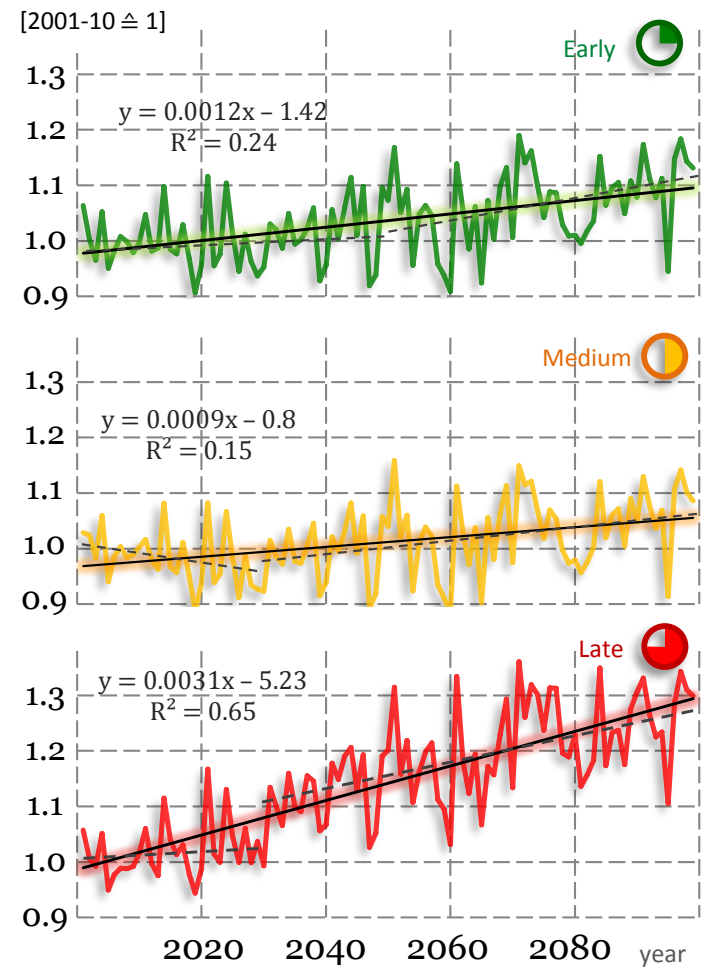

Figure 3. Maize yield development in relation to the mean of 2001-2010 for the three varieties. The black lines and data indicate the linear trend over the century. Dotted lines represent two linear trends during the century with a breaking point at 2050 (early) or 2030 (medium and late variety).

Maize yield development in Lower Saxony

J. F. Degener and M. Kappas

Title Page

Abstract Introduction

Conclusions References

Tables Figures

14

\section{$\triangleleft$}

Back

Close

Printer-friendly Version

Interactive Discussion 


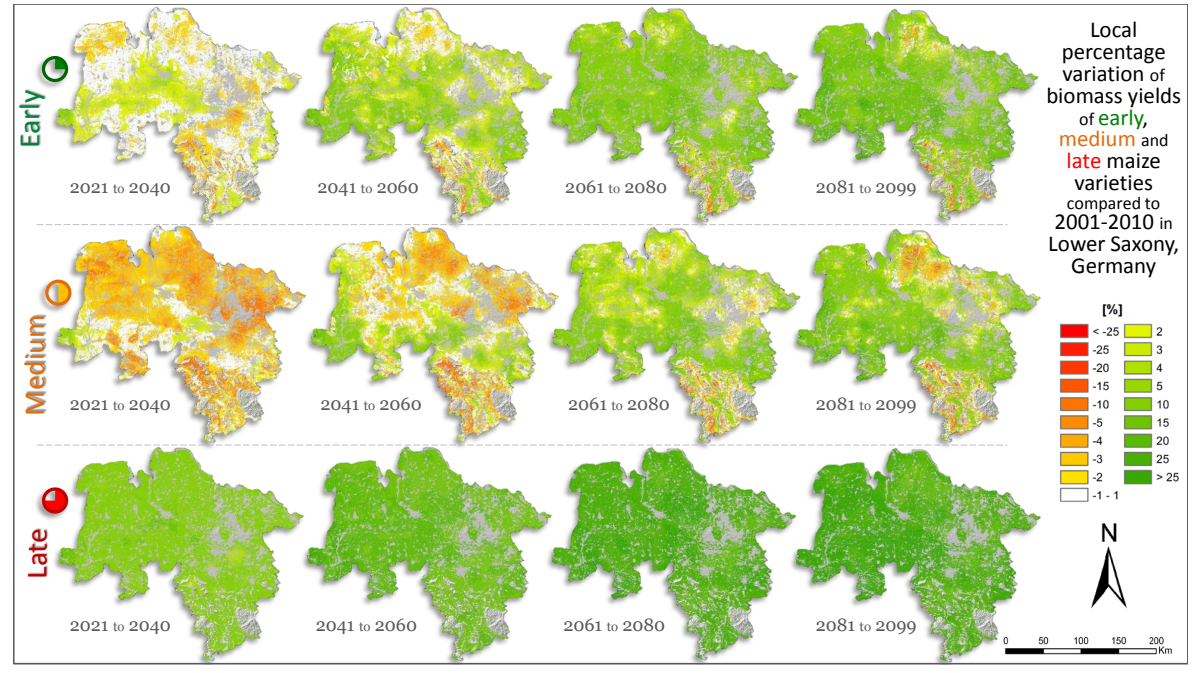

Figure 4. Local percentage variation of biomass yields of early, medium and late maize varieties compared to 2001-2010.

\section{BGD}

11, 9103-9134, 2014

Maize yield development in

Lower Saxony

J. F. Degener and M. Kappas

Title Page

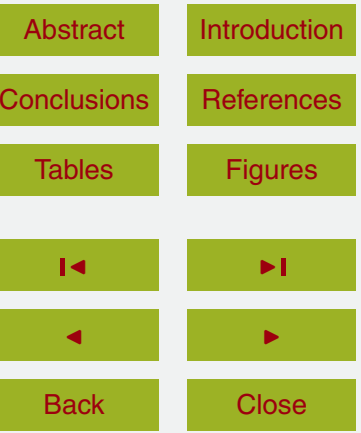

Full Screen / Esc

Printer-friendly Version

Interactive Discussion 


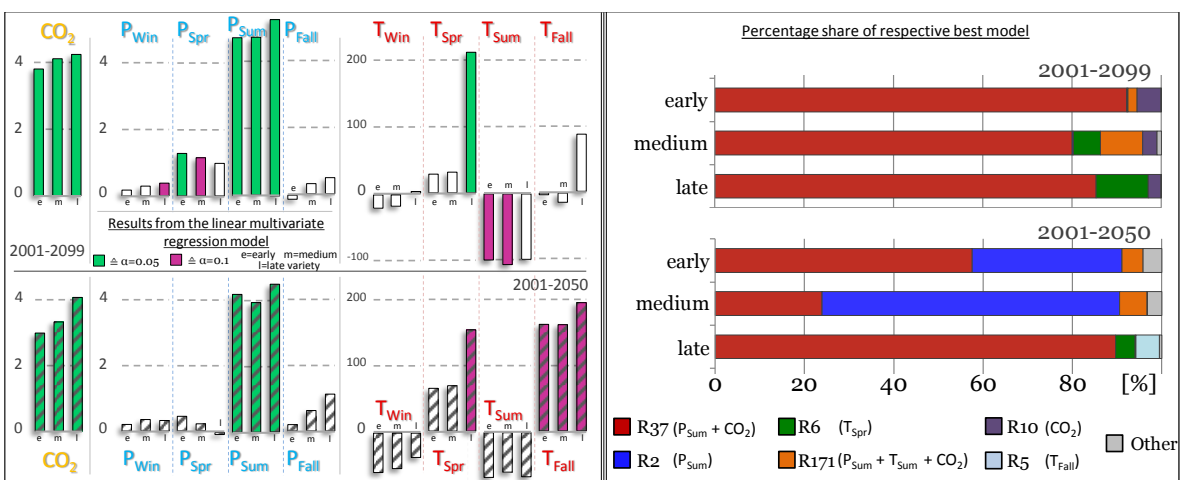

Figure 5. Left side: output of 9 variables from the linear multivariate regression analysis for 2001-2099 (top) and 2001-2050 (bottom) - Right side: relative share of different linear (multivariate) models to the total number of models $R_{X}$ represents the number of the 2047 possible runs through variable combination $-P_{X}$ is precipitation by respective season, $T_{X}$ for temperature.
BGD

$11,9103-9134,2014$

Maize yield

development in

Lower Saxony

J. F. Degener and

M. Kappas

Title Page

Abstract

Introduction

Conclusions

References

Tables

Figures

14

- I

Back

Close

Full Screen / Esc

Printer-friendly Version

Interactive Discussion 